\title{
Identification of a novel SEREX antigen, SLC2A1/GLUT1, in esophageal squamous cell carcinoma
}

\author{
MARI KUBOSHIMA ${ }^{1,2 *}$, HIDEAKI SHIMADA ${ }^{1 *}$, TIAN-LING LIU ${ }^{1,2}$, KAZUE NAKASHIMA ${ }^{1,2}$, \\ FUMIO NOMURA $^{3}$, MASAKI TAKIGUCHI $^{2}$, TAKAKI HIWASA $^{2}$ and TAKENORI OCHIAI ${ }^{1}$ \\ Departments of ${ }^{1}$ Frontier Surgery, ${ }^{2}$ Biochemistry and Genetics, and ${ }^{3}$ Molecular Diagnosis, Chiba University \\ Graduate School of Medicine, Inohana 1-8-1, Chuo-ku, Chiba 260-8670, Japan
}

Received September 12, 2005; Accepted November 2, 2005

\begin{abstract}
We have carried out SEREX (serological identification of antigens by recombinant cDNA expression cloning), and identified SLC2A1 (solute carrier family 2/facilitated glucose transporter, member 1) as an antigen recognized by serum IgG antibodies in patients with esophageal squamous cell carcinoma (SCC). The levels of serum anti-SLC2A1 antibodies (s-SLC2A1-Abs), examined by enzyme-linked immunosorbent assay using bacterially expressed glutathioneS-transferase-SLC2A1 fusion protein, were significantly higher in patients with esophageal SCC than in healthy donors. When using a cut-off level as the mean $+2 \mathrm{x}$ standard deviations of healthy donors, a total of $12(21 \%)$ out of 57 SCC patients were revealed as positive for s-SLC2A1-Abs. The presence of s-SLC2A1-Abs was not associated with either clinicopathological factors or survival. Because s-SLC2A1-Abs were not associated with the positivity of other conventional serum markers, a combination assay of s-SLC2A1-Abs with these conventional serum markers may be useful for the diagnosis and monitoring of esophageal SCC.
\end{abstract}

\section{Introduction}

It has been well documented that tumor markers are indispensable for the early detection of cancer. Although several serum tumor markers have been linked with esophageal carcinoma, only limited positivity has been reported for esophageal squamous cell carcinoma (SCC) (1-5). SEREX (serological identification of antigens by recombinant cDNA expression cloning) is an effective and convenient method

Correspondence to: Dr Takaki Hiwasa, Department of Biochemistry and Genetics, Chiba University Graduate School of Medicine, Inohana 1-8-1, Chuo-ku, Chiba 260-8670, Japan

E-mail: hiwasa_takaki@faculty.chiba-u.jp

${ }^{*}$ Contributed equally

Key words: SEREX, esophageal squamous cell carcinoma, tumor antigen, ELISA, SLC2A1 for identifying tumor markers (6). This involves the immunoscreening of cDNA libraries, prepared from tumor specimens, with autologous or allogeneic sera. Since the antigens are easily identified by sequencing the isolated cDNA clones, SEREX is suitable for the large-scale screening of tumor antigens. SEREX has been applied to a variety of tumor types, and more than 1000 SEREX antigens have already been identified (7).

A previous application of the SEREX method to esophageal cancer resulted in the identification of NY-ESO-1, which is a cancer-testis antigen that is expressed in various cancer cells (8). In addition, SEREX analysis has led to the isolation of several antigens known to be related to cancer, including the p53 tumor suppressor protein. Serum antibodies to p53 have been used for the detection of superficial cancers and in the prediction of a poor prognosis for patients with esophageal SCC (9-11).

We have applied the SEREX methodology to esophageal SCC with the aim of adding to the catalogue of defined immunogenic proteins in human cancer, and have previously reported several new SEREX antigens of esophageal SCC such as TROP2, SURF1 and HOOK2 $(12,13)$. In the present study, we have identified SLC2A1/GLUT1 as a new SEREX antigen. This provides a potentially new diagnostic method for esophageal SCC, i.e. the examination of SLC2A1 antibody levels in sera instead of SLC2A1 antigen expression levels in tumor tissue.

\section{Materials and methods}

Human esophageal squamous cell carcinoma cDNA libraries. This study was approved by the local ethics review board of Chiba University Graduate School of Medicine. Recombinant DNA work was conducted with official permission and in accordance with the rules of the government of Japan. All patients gave their written informed consent before participating in the study. A human esophageal SCC cell line, T.Tn, was established by the Department of Clinical Molecular Biology, Chiba University Graduate School of Medicine $(14,15)$. Total RNA was prepared from T.Tn cells by the acid guanidium thiocyanate-phenol-chloroform method and purified to poly(A)+ RNA using an Oligotex-dT ${ }_{30}$ (Super) mRNA purification kit (Takara Biochemicals, Kyoto, Japan) according to the manufacturer's instructions (16). cDNA was ligated into the 
EcoRI-XhoI site of the $\lambda$ ZAP II phage. The original library size was $1.8 \times 10^{6}$.

Patients and healthy donor sera. Sera were obtained from 57 patients with esophageal SCC before treatment was started, and from 31 healthy donors. The SCC patients consisted of 51 men $(89 \%)$ and 6 women $(11 \%)$, with a median age of 65 years (range 44-82 years). They were pathologically classified according to the Tumor Node Metastasis/Union Internationale Contre Cancer (pTNM/UICC) classification (17) as follows: stage I cancer $(n=19)$, stage II $(n=6)$, stage III $(n=13)$ and stage IV $(n=19)$. After the operation, patients were followed-up with clinical examinations and imaging studies on a regular basis until death or the end of March 2005. The mean follow-up time for survivors was 26 months. Each sample was centrifuged at 3,000 x g for $5 \mathrm{~min}$ and then frozen at $-80^{\circ} \mathrm{C}$ until use. Repeated thawing and freezing of samples was avoided.

CEA, CYFRA-Ag and SCC-Ag assays. Serum carcinoembryonic antigen (CEA) and CYFRA-Ag concentrations were measured with Enzymun-Test CEA and Enzymun-Test CYFRA21-1 (Boehringer Mannheim, Mannheim, Germany), respectively. Serum SCC-Ag levels were measured using the SCC Test (Abbott Laboratories, Abbott Park, IL). The cut-off values for serum CEA, CYFRA-Ag and SCC-Ag were 4.6, 2.57 and $1.5 \mathrm{ng} / \mathrm{ml}$, respectively, in accordance with the manufacturer's instructions. The specificity at these cut-off values is $95 \%(4,5)$.

Immunological screening of esophageal carcinoma cell antigens by SEREX. Esophageal carcinoma antigens were screened using the SEREX method previously published by Sahin et al (6). E. coli XL1-Blue MRF' was infected with $\lambda$ ZAP II phage which contained cDNA library, and the expression of cDNA was induced by blotting on nitrocellulose membranes (NitroBind, Osmonics Inc., Minnetonka, MN), which had been pretreated for $30 \mathrm{~min}$ with $10 \mathrm{mM}$ isopropyl B-D-thiogalactoside (IPTG; Wako Pure Chemicals, Osaka, Japan). The membranes were then washed three times with TBS-T [20 mM Tris- $\mathrm{HCl}$ (pH 7.5), $0.15 \mathrm{M} \mathrm{NaCl}$ and $0.05 \%$ Tween-20], and blocking was performed by treatment with $1 \%$ protease-free bovine serum albumin (Wako Pure Chemicals) in TBS-T for $1 \mathrm{~h}$. The membranes were exposed in 1:2,000diluted serum for $1 \mathrm{~h}$. After washing with TBS-T three times, the membranes were treated with 1:5,000-diluted alkaline phosphatase-conjugated $\mathrm{F}(\mathrm{ab})^{\prime}$ fragment-specific goat antihuman IgG (Jackson ImmunoResearch Laboratories, West Grove, PA) for $1 \mathrm{~h}$. Positive reactions were detected by incubation in color development solution [100 mM Tris-HCl (pH 9.5), $100 \mathrm{mM} \mathrm{NaCl}$ and $5 \mathrm{mM} \mathrm{MgCl}{ }_{2}$ ] containing $0.3 \mathrm{mg} /$ $\mathrm{ml}$ of nitroblue tetrazolium chloride (Wako Pure Chemicals) and $0.15 \mathrm{mg} / \mathrm{ml}$ of 5-bromo-4-chloro-3-indolyl-phosphate (Wako Pure Chemicals). Positive clones were recloned twice to obtain monoclonality and retested for serum reactivity.

Sequence analysis of identified antigens. Monoclonalized phage cDNA clones were converted to pBluescript phagemids by in vivo excision using ExAssist helper phage (Stratagene, La Jolla, CA). Plasmid DNA was obtained from E. coli SOLR strain transformed by the phagemid. The cDNA inserts were sequenced by the dideoxy chain termination method using the DNA sequencing kit BigDye ${ }^{\mathrm{TM}}$ Terminator (Applied Biosystems, Foster City, CA) and ABI PRISM 3700 DNA analyzer (Applied Biosystems). Sequences were analyzed for homology with public databases of known genes and proteins using NCBI-BLAST.

Purification of recombinant SLC2A1 protein. cDNA insert of SLC2A1 incorporated in pBluescript was cleaved by EcoRI and XhoI, and recombined in pGEX-4T-3. E. coli JM109 cells containing pGEX-4T-3-SLC2A1 or control pGEX-4T-3 were cultured in $200 \mathrm{ml}$ of Luria broth (LB) and treated with $1 \mathrm{mM}$ IPTG for $2.5 \mathrm{~h}$. Cells were harvested, washed with phosphate-buffered saline (PBS) and lysed by sonication in $10 \%$ Triton $\mathrm{X}-100,50 \mathrm{mM}$ Tris- $\mathrm{HCl}$ (pH 8.0), 1 mM ethylenediaminetetraacetic acid (EDTA) and $1 \mathrm{mM}$ dithiothreitol (DTT). The lysate was then centrifuged at $10,000 \mathrm{x} g$ for $30 \mathrm{~min}$ at $4^{\circ} \mathrm{C}$. Glutathione-S-transferase (GST) was harvested in the supernatant, and directly purified by glutathione-Sepharose. GST-SLC2A1 recovered in the pellet was suspended in $8 \mathrm{M}$ urea, $50 \mathrm{mM}$ Tris- $\mathrm{HCl}$ (pH 8.0), $1 \mathrm{mM}$ EDTA and $1 \mathrm{mM}$ DTT, and dialyzed stepwise against $4 \mathrm{M}$ urea, $50 \mathrm{mM}$ Tris- $\mathrm{HCl}$ ( $\mathrm{pH} 8.0), 1 \mathrm{mM}$ EDTA and $1 \mathrm{mM}$ DTT for $1 \mathrm{~h}, 2 \mathrm{M}$ urea, $50 \mathrm{mM}$ Tris- $\mathrm{HCl}$ (pH 8.0), $1 \mathrm{mM}$ EDTA and $1 \mathrm{mM}$ DTT for $1 \mathrm{~h}$, and then $50 \mathrm{mM} \mathrm{NaCl}, 50 \mathrm{mM}$ Tris- $\mathrm{HCl}(\mathrm{pH} 8.0), 1 \mathrm{mM}$ EDTA and $1 \mathrm{mM}$ DTT for $>12 \mathrm{~h}$. The samples were centrifuged at $10,000 \mathrm{x} \mathrm{g}$ for $10 \mathrm{~min}$ at $4^{\circ} \mathrm{C}$ and affinity-purified by glutathione-Sepharose (Amersham Biosciences, Piscataway, $\mathrm{NJ}$ ). The purified proteins were concentrated using Apollo centrifugal concentrators (Orbital Biosciences, Topsfield, MA).

Western blot analysis. E. coli JM109 cells which contained cDNA clones recombined in pGEX-4T-3 or pGEX-4T-2 were cultured with or without $1 \mathrm{mM}$ IPTG for $2.5 \mathrm{~h}$. Cells were then washed with PBS and lysed by incubation at $100^{\circ} \mathrm{C}$ for $3 \mathrm{~min}$ in SDS sample buffer (18). E. coli lysate was then subjected to SDS-PAGE followed by Western blotting using sera of patients or healthy donors.

Enzyme-linked immunosorbent assay (ELISA) using bacterially expressed glutathione-S-transferase-SLC2A1 fusion protein. Antigens $(50 \mu \mathrm{l})(\mathrm{GST}$ or GST-SLC2A1) diluted at $10 \mu \mathrm{g}$ protein $/ \mathrm{ml}$ in PBS were added to the wells of a microtiter plate, and incubated at room temperature overnight. The plate was washed 4 times with $0.1 \%$ Tween-20 in PBS (PBS-T) and then blocked with $10 \%$ fetal calf serum in PBS (PBS-FCS). The plate was incubated at room temperature for $1 \mathrm{~h}$ and washed 4 times with PBS-T. Sera $(50 \mu 1)$ diluted at 1/100 in PBS-FCS were added to the wells and incubated for $1 \mathrm{~h}$. The wells were washed with PBS-T 4 times and the bound IgG antibodies were detected by incubation with horseradish peroxidase-conjugated anti-human IgG antibody (Jackson ImmunoResearch Laboratories, West Grove, PA) for $1 \mathrm{~h}$, followed by washing and the addition of $100 \mu 1$ of a peroxidase substrate (o-phenylenediamine, $0.4 \mathrm{mg} / \mathrm{ml}$ ) in citrate-phosphate buffer, $\mathrm{pH} 5.0$, containing $0.02 \%(\mathrm{v} / \mathrm{v}) \mathrm{H}_{2} \mathrm{O}_{2}$. The reaction was stopped with $30 \mu \mathrm{l}$ of $22 \% \mathrm{H}_{2} \mathrm{SO}_{4}$. Absorbance at $490 \mathrm{~nm}$ was determined by using a microplate reader (Emax, Molecular Devices, Sunnyvale, CA). 
A

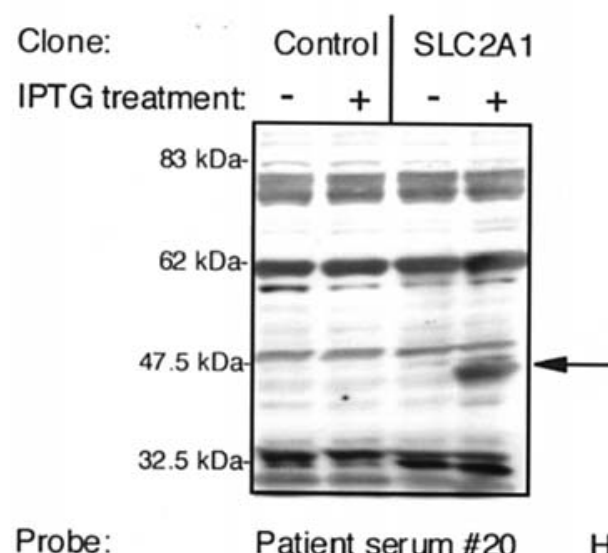

B

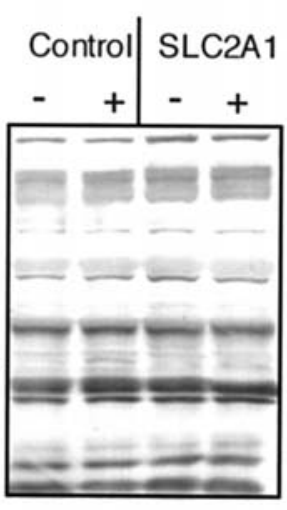

Healthy donor serum \#1
C

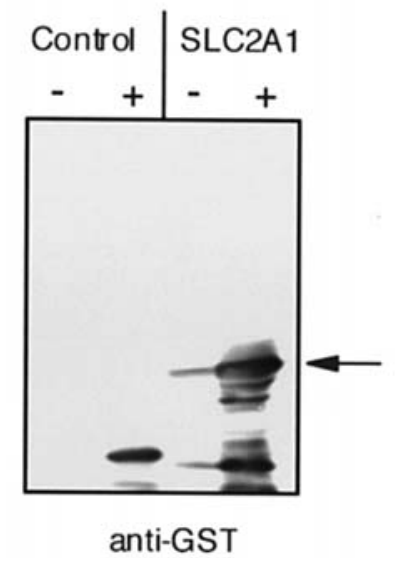

Figure 1. Recognition of SLC2A1 by serum antibodies in patients with esophageal SCC. E. coli containing pGEX-4T-3-SLC2A1 (SLC2A1) or control pGEX-4T2-SLC2A1 (control, SLC2A1 frameshift product) was treated with or without IPTG for $2.5 \mathrm{~h}$. Cell lysates were subsequently subjected to Western blot analysis using esophageal cancer patient serum \#20 (A), or healthy donor serum \#1 (B). The same samples were also probed with anti-GST-antibody (C). An arrow indicates the IPTG-induced polypeptide that represents SLC2A1 cDNA product.

Statistical analyses. Survival probabilities were calculated using the product-limit method of Kaplan and Meier, considering all deaths. Survival differences between groups were determined using the log-rank test. Fisher's exact probability test and the Mann-Whitney $U$ test were used to determine the significance of the differences between two groups. All statistical analyses were carried out using the StatView 5.0J program for Windows (SAS Institute Inc., Cary, NC). P-values $<0.05$ were considered statistically significant.

\section{Results}

Serological screening of cDNA library. Phage expression library was constructed from the mRNA of an esophageal cancer cell line, T.Tn. A total of $1 \times 10^{6}$ clones of cDNA were screened using serum from a patient with esophageal SCC, and 13 reactive clones were isolated. DNA sequence analysis and an homology search using the National Center for Biotechnology Information (NCBI) databases revealed SLC2A1 [Solute carrier family 2 (facilitated glucose transporter), member 1] (Accession number: NM_006516), which was further investigated in this study. SLC2A1 is a member of the membrane transporter (SLC) family, and is an integral membrane glycoprotein involved in transporting glucose into cells (19). The chromosomal position of SLC2A1 is 1p35p31.3, and the product consists of 492 amino acids $(54,117$ $\mathrm{Da}$ ). The isolated clone contained the region between aminoacid positions 292 and 492 (approximately $22 \mathrm{kDa}$ ). SLC2A1 is not listed as a SEREX antigen in the cancer immunome database (7). However, its family member, SLC2A11 (NM_030807), which is also a glucose transporter but located at a different locus (22q11.2), is listed as a SEREX antigen of pancreatic adenocarcinoma, melanoma and fibrosarcoma.

Presence of serum SLC2A1 antibodies in patients with esophageal squamous cell carcinoma. To confirm the presence of serum SLC2A1 antibodies (s-SLC2A1-Abs) in patients with esophageal SCC, Western blotting was performed using

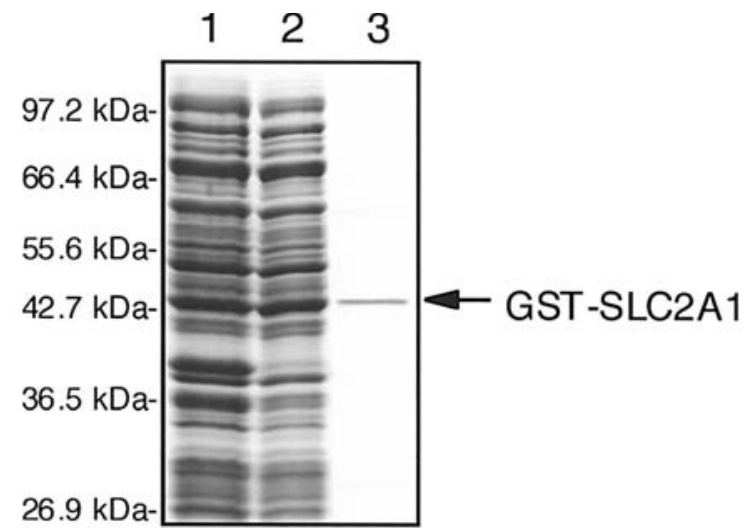

Figure 2. SDS-PAGE after purification of recombinant SLC2A1 protein. Lane 1, whole bacterial lysates; lane 2, supernanant of Triton X-100 lysate; lane 3 , purified fraction after glutathione-Sepharose affinity-column chromatography.

bacterially-expressed SLC2A1 protein. The expression vector was constructed by ligation of EcoRI/XhoI insert of SLC2A1 in pBluescript in pGEX-4T-3, which produces GST-SLC2A1 fusion protein after treating $E$. coli with IPTG. As a control, the SLC2A1 insert was inserted in the EcoRI/XhoI site of pGEX-4T-2, which produced a frameshift mutation and an early translational termination. Fig. 1 shows representative positive and negative results of s-SLC2A1-Abs. When the $E$. coli extracts were probed with anti-GST antibody, the reaction of polypeptides of approximately 33 and $47 \mathrm{kDa}$ was markedly enhanced by treatment with IPTG (Fig. 1C), suggesting that these bands were IPTG-induced GST-fusion proteins. The size of $47 \mathrm{kDa}$ was almost equal to the estimated size of the fusion protein of pGEX-4T-encoded GST (25 kDa) and amino-terminal truncated SLC2A1 protein $(22 \mathrm{kDa})$. This polypeptide was also observed in the serum from patient \#20 (P\#20) but not in the serum from healthy donor \#1 (HD\#1) (Fig. 1A and B). Control polypeptide did not react with the serum from patient \#20 or healthy donor \#1. These results 


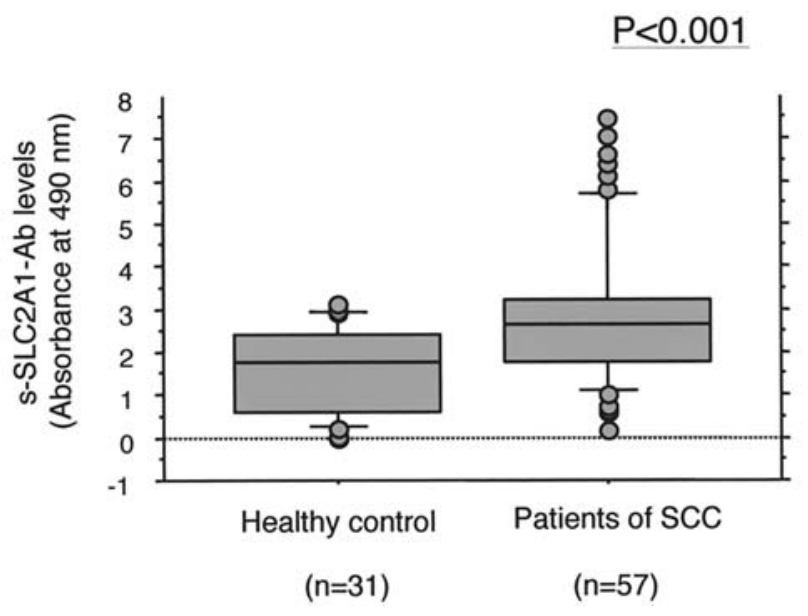

Figure 3. Results of ELISA. The levels of s-SLC2A1-Abs were measured by ELISA using purified GST-SLC2A1 protein and control GST protein. The boxplots display the 10th, 25th, 50th (bold horizontal line is the median), 75th and 90th percentiles. P-values calculated by the Mann-Whitney test were found to be $<0.001$ between levels of s-SLC2A1-Abs in patients versus healthy donors.

indicated that the serum of P\#20 was positive for s-SLC2A1Abs while the serum of HD\#1 was negative.

To analyze the levels of s-SLC2A1-Abs quantitatively, we performed ELISA by using recombinant antigen protein. GSTSLC2A1 fusion protein was induced by treatment with IPTG, and affinity-purified by glutathione-Sepharose. The reactive levels against control GST were subtracted from those against GST-SLC2A1 of each serum sample. The mean ( \pm SD) serum antibody levels of patients with esophageal SCC were 2.892 $( \pm 1.662)$, which were significantly higher than those of healthy donors $(1.588 \pm 0.982)(\mathrm{P}<0.001$, Fig. 3).

The levels of s-SLC2A1-Abs were divided into two groups with a border value of 3.552 which was the mean + two standard deviations of s-SLC2A1-Abs of healthy donors. The positive rate of patients with esophageal SCC was $21 \%$ (12 out of 57) while no healthy donors were positive for s-SLC2A1Abs.

We then examined the relationship between the presence of s-SLC2A1-Abs and clinicopathological features of the patients (Table I). There was no correlation between the presence of s-SLC2A1-Abs and clinicopathological variables such as location, tumor depth and TNM factors. Because there was no association between the presence of s-SLC2A1Abs and positivity of other serum markers, a combination assay using conventional serum markers and s-SLC2A1-Abs revealed high positive rates (32, 37 and 47\%, respectively; Fig. 4). Although sero-positive patients showed better survival rates than sero-negative patients, the difference was not statistically significant (Fig. 5).

\section{Discussion}

SEREX screening for esophageal carcinomas has previously been performed by Chen et al (8) and Tureci et al (20), and NY-ESO-1 and NY-ESO-2 have been identified. In the present study, we identified SLC2A1 as a new SEREX antigen of esophageal SCC. The levels of s-SLC2A1-Abs were significantly higher in patients with esophageal SCC than in healthy donors.
Table I. Relationship between s-SLC2A1-Abs and the clinicopathological variables in 57 patients with esophageal SCC.

\begin{tabular}{|c|c|c|}
\hline $\begin{array}{l}\text { Variables } \\
\text { (No. of patients) }\end{array}$ & $\begin{array}{l}\text { No. of patients with } \\
\text { s-SLC2A1-Abs } \\
\text { (positive rate, \%) }\end{array}$ & P-value ${ }^{a}$ \\
\hline \multicolumn{3}{|l|}{ Gender } \\
\hline Male (50) & $12(24)$ & \\
\hline Female (7) & $\begin{array}{ll}0 & (0)\end{array}$ & 0.325 \\
\hline \multicolumn{3}{|l|}{ Age } \\
\hline$\leq 65(30)$ & $6(20)$ & \\
\hline$>65(27)$ & $6(22)$ & $>0.999$ \\
\hline \multicolumn{3}{|l|}{ Location } \\
\hline Upper (15) & $3(20)$ & \\
\hline Lower (42) & $9(21)$ & $>0.999$ \\
\hline \multicolumn{3}{|l|}{ Tumor size } \\
\hline$\leq 40 \mathrm{~mm}(33)$ & $5(15)$ & \\
\hline$>40 \mathrm{~mm}(24)$ & $7(29)$ & 0.324 \\
\hline \multicolumn{3}{|l|}{ Tumor depth } \\
\hline $\mathrm{T} 1, \mathrm{~T} 2(26)$ & $5(19)$ & \\
\hline T3,T4 (31) & $7(23)$ & $>0.999$ \\
\hline \multicolumn{3}{|l|}{$\mathrm{N}$ factor } \\
\hline N0 (22) & $4(18)$ & \\
\hline N1 (35) & $8(23)$ & $>0.999$ \\
\hline \multicolumn{3}{|l|}{ M factor } \\
\hline M0 (51) & $10(20)$ & \\
\hline M1 (6) & $2(33)$ & 0.596 \\
\hline \multicolumn{3}{|l|}{ Stage } \\
\hline $\mathrm{I}(18)$ & $4(22)$ & \\
\hline II, III, IV (39) & $8(21)$ & $>0.999$ \\
\hline \multicolumn{3}{|l|}{ CYFRA-Ag } \\
\hline Positive (8) & $2(29)$ & \\
\hline Negative (49) & $10(20)$ & 0.670 \\
\hline \multicolumn{3}{|l|}{ SCC-Ag } \\
\hline Positive (13) & $4(31)$ & \\
\hline Negative (44) & $8(18)$ & 0.440 \\
\hline \multicolumn{3}{|l|}{ CEA-Ag } \\
\hline Positive (20) & $5(25)$ & \\
\hline Negative (37) & 7 (19) & 0.736 \\
\hline
\end{tabular}

aP-values were calculated by Fisher's exact probability test.

Such a clear difference between patients and healthy donors suggests that s-SLC2A1-Abs may be a useful diagnostic marker for esophageal SCC.

SLC2A1/GLUT1 has been reported to be overexpressed in tumor tissue from lung (21), gastric (22), head and neck (23) and pancreatic (24) cancers. Expression of SLC2A1 has been observed in all of 72 esophageal cancer tissues examined 


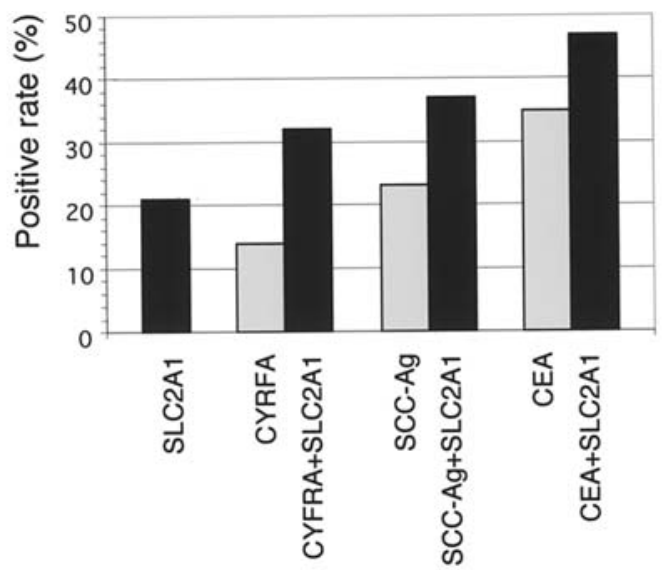

Figure 4. Positive rate in combination assay of serum markers with s-SLC2A1Abs. Gray box indicated positive rates of conventional serum markers. Black box indicated positive rates of conventional serum markers when used in combination with s-SLC2A1-Abs (32, 37 and 47\%, respectively).

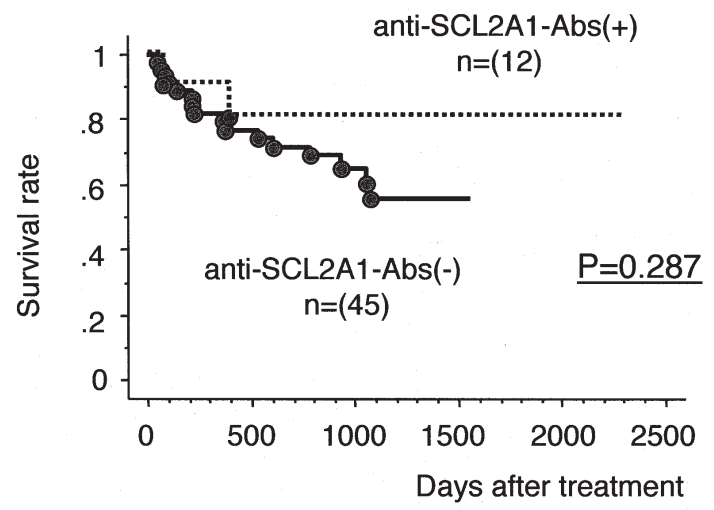

Figure 5. Kaplan-Meier survival curves for positive and negative cases of esophageal SCC with respect to detection of s-SLC2A1-Abs. No significant difference was seen between the two curves by the log-rank test.

(25). There are five members of the glucose transporter family. Matsuzu et al have reported that SLC2A1/GLUT1 but not SLC2A2/GLUT2, SLC2A3/GLUT3, SLC2A4/GLUT4 nor SLC2A11 (GLUT10/11) was overexpressed in thyroid carcinoma compared to normal tissue (26). The expression of SLC2A1 is transcriptionally regulated by the oncogene product, c-Myc (27). The suppression of SLC2A1 expression by antisense mRNA inhibited tumor cell growth (28). Among glucose transporter family members, only SLC2A1 may be a necessary factor for the rapid growth of tumor cells.

Solute carrier proteins are engaged in the transport of small molecules across membranes. Although SLC2A1/GLUT1 has not yet been reported as a SEREX antigen, other SLC family members, such as SLC22A17, SLC25A2, SLC25A20, SLC25A6, SLC4A1AP, SLC4A5, SLC9A3R2 and SLC06A1, have been identified as SEREX antigens in the cancer immunome database (7). For example, SLC2A11 is a SEREX antigen of pancreatic adenocarcinoma, melanoma and fibrosarcoma. It should be noted that SEREX screening identifies not only the original antigen but also other proteins which have the same epitope structure. This raises the possibility that some, if not all, solute carrier proteins might have been isolated by SEREX as cross-reactive proteins recognized by anti-SLC2A1 antibodies.

Because SLC2A1 is highly expressed in many cancer tissues, SLC2A1 is an appropriate molecular target for the diagnosis of cancer. The present study showed that the serum levels of SLC2A1 antibodies were significantly higher in patients with esophageal SCC than in healthy donors. We had previously reported that serum p53 antibodies are a useful marker for esophageal SCC (9-11). Thus, s-SLC2A1-Abs may also become available as a rapid and convenient diagnostic method for esophageal SCC and various other types of cancer. Because s-SLC2A1-Abs were not associated with the positivity of other conventional serum markers (Table I), a combination assay of s-SLC2A1-Abs with these conventional serum markers may further improve the diagnostic efficiency of esophageal SCC.

\section{Acknowledgements}

We thank Ms. Masae Suzuki and Ayumi Shioya for their helpful technical assistance. This study was partly supported by the 21st Century COE (Center of Excellence) Program Grant and a Grant-in-Aid for Scientific Research from the Ministry of Education, Culture, Sports, Science and Technology of Japan.

\section{References}

1. Kim YH, Ajani JA, Ota DM, Lynch P and Roth JA: Value of serial carcinoembryonic antigen levels in patients with resectable adenocarcinoma of the esophagus and stomach. Cancer 75: 451-456, 1995.

2. Munck-Wikland E, Kuylenstierna R, Wahren B, Lindholm J and Haglund S: Tumor markers carcinoembryonic antigen, CA 50, and CA 19-9 and squamous cell carcinoma of the esophagus. Pretreatment screening. Cancer 62: 2281-2286, 1988.

3. McKnight A, Mannell A and Shperling I: The role of carbohydrate antigen 19-9 as a tumour marker of oesophageal cancer. Br J Cancer 60: 249-251, 1989.

4. Shimada H, Nabeya Y, Okazumi S, Matsubara H, Shiratori T, Gunji Y, Kobayashi S, Hayashi H and Ochiai T: Prediction of survival with squamous cell carcinoma antigen in patients with resectable esophageal squamous cell carcinoma. Surgery 133: 486-494, 2003.

5. Shimada H, Nabeya Y, Okazumi S, Matsubara H, Miyazawa Y, Shiratori T, Hayashi H, Gunji Y and Ochiai T: Prognostic significance of CYFRA21-1 in patients with esophageal squamous cell carcinoma. J Am Coll Surg 196: 573-578, 2003.

6. Sahin U, Tureci O, Schmitt H, Cochlovius B, Johannes T, Schmits R, Stenner F, Luo G, Schobert I and Pfreundschuh M: Human neoplasms elicit multiple specific immune responses in the autologous host. Proc Natl Acad Sci USA 92: 11810-11813, 1995.

7. Cancer immunome database: http://www2.licr.org/Cancer ImmunomeDB/.

8. Chen YT, Boyer AD, Viars CS, Tsang S, Old LJ and Arden KC: Genomic cloning and localization of CTAG, a gene encoding an autoimmunogenic cancer-testis antigen NY-ESO-1, to human chromosome Xq28. Cytogenet Cell Genet 79: 237-240, 1997.

9. Shimada H, Takeda A, Arima M, Okazumi S, Matsubara H, Nabeya Y, Funami Y, Hayashi H, Gunji Y, Suzuki T, Kobayashi S and Ochiai T: Serum p53 antibody is a useful tumor marker in superficial esophageal squamous cell carcinoma. Cancer 89: 1677-1683, 2000.

10. Shimada H, Nabeya Y, Okazumi S, Matsubara H, Funami Y, Shiratori T, Hayashi H, Takeda A and Ochiai T: Prognostic significance of serum p53 antibody in patients with esophageal squamous cell carcinoma. Surgery 132: 41-47, 2002.

11. Shimada H, Ochiai T and Nomura F: Titration of serum p53 antibodies in 1085 patients with various cancers. A multi institutional analysis by Japan p53 antibody research group. Cancer 97: 682-689, 2003. 
12. Nakashima K, Shimada H, Ochiai T, Kuboshima M, Kuroiwa N, Okazumi S, Matsubara H, Nomura F, Takiguchi M and Hiwasa T: Serological identification of TROP2 by recombinant cDNA expression cloning using sera of patients with esophageal squamous cell carcinoma. Int J Cancer 112: 1029-1035, 2004.

13. Shimada H, Nakashima N, Ochiai T, Nabeya Y, Takiguchi M, Nomura $F$ and Hiwasa T: Serological identification of tumor antigens of esophageal squamous cell carcinoma. Int J Oncol 26: 77-86, 2005 .

14. Takahashi K, Kanazawa H, Chan H, Hosono T, Takahara M and Sato K: A case of esophageal carcinoma metastatic to the mandible and characterization of two cell lines (T.T. and T.Tn.). Jpn J Oral Maxillofac Surg 36: 307-316, 1990

15. Shimada H, Shimizu T, Ochiai T, Liu T-L, Sashiyama H, Nakamura A, Matsubara H, Gunji Y, Kobayashi S, Tagawa M, Sakiyama S and Hiwasa T: Preclinical study of adenoviral p53 gene therapy for esophageal cancer. Surg Today 31: 597-604, 2001.

16. Chomczynski P and Sacchi N: Single-step method of RNA isolation by acid guanidinium thiocyanate-phenol-chloroform extraction. Anal Biochem 162: 156-159, 1987.

17. Sobin LH and Wittekind CH (eds): UICC TNM Classification of Malignant Tumors. 6th edition. John Wiley \& Sons, Inc., New York, 2000.

18. Laemmli U: Cleavage of structural proteins during the assembly of the head of bacteriophage. Nature 227: 680-685, 1970.

19. Mueckler M, Caruso C, Baldwin SA, Panico M, Blench I, Morris HR, Allard WJ, Lienhard GE and Lodish HF: Sequence and structure of a human glucose transporter. Science 229: 941-945, 1985

20. Tureci O, Sahin U, Zwick C, Koslowski M, Seitz G and Pfreundschuh M: Identification of a meiosis-specific protein as a member of the class of cancer/testis antigens. Proc Natl Acad Sci USA 95: 5211-5216, 1998.
21. Kurata T, Oguri T, Isobe T, Ishioka S and Yamakido M: Differential expression of facilitative glucose transporter (GLUT) genes in primary lung cancers and their liver metastases. Jpn J Cancer Res 90: 1238-1243, 1999.

22. Noguchi Y, Marat D, Saito A, Yoshikawa T, Doi C, Fukuzawa K, Tsuburaya A, Satoh S and Ito T: Expression of facilitative glucose transporters in gastric tumors. Hepatogastroenterology 46: 2683-2689, 1999.

23. Reisser C, Eichhorn K, Herold-Mende C, Born AI and Bannasch P: Expression of facilitative glucose transport proteins during development of squamous cell carcinomas of the head and neck. Int J Cancer 80: 194-198, 1999.

24. Higashi T, Tamaki N, Torizuka T, Nakamoto Y, Sakahara H, Kimura T, Honda T, Inokuma T, Katsushima S, Ohshio G, Imamura M and Konishi J: FDG uptake, GLUT-1 glucose transporter and cellularity in human pancreatic tumors. J Nucl Med 39: $1727-1735,1998$

25. Tohma T, Okazumi S, Makino H, Cho A, Mochiduki R, Shuto K, Kudo H, Matsubara K, Gunji H and Ochiai T: Relationship between glucose transporter, hexokinase and FDG-PET in esophageal cancer. Hepatogastroenterology 52: 486-490, 2005.

26. Matsuzu K, Segade F, Matsuzu U, Carter A, Bowden DW and Perrier ND: Differential expression of glucose transporters in normal and pathologic thyroid tissue. Thyroid 14: 806-812, 2004.

27. Osthus RC, Shim H, Kim S, Li Q, Reddy R, Mukherjee M, Xu Y, Wonsey D, Lee LA and Dang CV: Deregulation of glucose transporter 1 and glycolytic gene expression by c-Myc. J Biol Chem 275: 21797-21800, 2000.

28. Noguchi Y, Saito A, Miyagi Y, Yamanaka S, Marat D, Doi C, Yoshikawa T, Tsuburaya A, Ito T and Satoh S: Suppression of facilitative glucose transporter 1 mRNA can suppress tumor growth. Cancer Lett 154: 1751-1782, 2000. 